\title{
Should salvage surgery be considered for local recurrence after definitive chemoradiation in locally advanced non- small cell lung cancer?
}

\author{
Waldemar Schreiner ${ }^{1 *}$ (D) Wojciech Dudek ${ }^{1}$, Sebastian Lettmaier ${ }^{2}$, Rainer Fietkau ${ }^{2}$ and Horia Sirbu ${ }^{1}$
}

\begin{abstract}
Background: Incidence of local relapse after definitive chemoradiation (>59 Gy) for locally advanced non-small-cell lung cancer (NSCLC) is high, irrespective of high dose radiation applied. Experience with salvage lung resections in patients with locally relapsed NSCLC after definitive chemoradiation is limited. We present our series of salvage lung resections for local NSCLC relapse after curative-intent chemoradiation for locally advanced tumor.

Methods: Nine consecutive patients with local tumor recurrence or persistence following definitive chemoradiation were reviewed. Kaplan-Meier analysis was used to assess patient survival.

Results: All patients received definitive radiation (median dose 66.2 Gy) with concurrent chemotherapy. Tumor stage prior to chemoradiation was IIIA in 8 patients and IV in 1. In 4 patients tumor invaded the chest wall, in 2 the spine and in 1 the aorta. Median interval between chemoradiation and salvage resection was 30.2 weeks. Nine patients underwent 9 resections ( 6 lobectomies, 1 bilobectomy, 1 pneumonectomy and 1 bi-segmentectomy). One death occurred on the 12th postoperative day. Median overall survival was 23 months; postoperative 3-year survival was $47 \%$. Median progression-free survival was 21 months.
\end{abstract}

Conclusion: Salvage lung resection for locally recurrent or persisted NSCLC in selected patients with locally advanced NSCLC following definitive chemoradiation is a worthwhile treatment option.

\section{Background}

Since the mid-1990s the definitive chemoradiation therapy (CRT) has been a commonplace treatment for unresectable locally advanced NSCLC, or for resectable tumors in surgical high-risk patients [1,2]. A local tumor relapse rate of up to $35 \%$ can be expected in patients after definitive CRT and remains the dominant cause of death after the initial therapy [3]. There is no consensus on the effective local treatment strategy. Treatment options such as reirradiation, chemotherapy, cryo- and radiofrequency ablation, observation only and/or salvage surgery are applied [4-6]. The term "salvage surgery" is traditionally used in the multimodal management of the rectal and anal cancer as a part of "watch and wait" policy and is usually

\footnotetext{
* Correspondence: waldemar.schreiner@uk-erlangen.de

'Department of Thoracic Surgery, University Hospital, Friedrich-Alexander

University Erlangen-Nuremberg, Erlangen, Germany

Full list of author information is available at the end of the article
}

indicated for late local recurrence and/or for incomplete clinical response after neo-adjuvant chemoradiation [7-9]. Recently this term was adopted into the thoracic oncology and represents a considerable treatment option for local NSCLC recurrence after stereotactic body radiation in patients with early stage tumor [9-12]. Moreover, the salvage lung resection seems to be technically feasible in patients previously chemoradiated for locally advanced NSCLC [13-16]. Due to the limited experience, the patient selection criteria for salvage resections remain unclear. We report on our series of patients who underwent salvage lung resections for local NSCLC relapse or tumor persistence following the definitive CRT.

\section{Methods}

The medical records of 9 consecutive patients, who underwent salvage lung resections at single institution between March 2011 and November 2013, were reviewed. All 
patients were treated for locally advanced NSCLC with a high dose radiation ( $>59$ Gy) and concurrent platinumbased chemotherapy with curative intent. Operative selection criteria were as follow: local recurrence of the tumor after completion of definitive CRT, presence of the residual tumor after definitive CRT and cardiorespiratory fitness. The local recurrence (5 patients) was a new pulmonary lesion with high standardized uptake value (SUV). The residual tumor (4 patients) was defined as persistence of the tumor in the chest CT with persistently high SUV after complete definitive CRT. The preoperative diagnostics included total body computed tomography (CT) and fluorodeoxyglucose positron emission tomography (FDG PET), cranial MRI and cardiorespiratory function testing. Patient demographics, NSCLC stage at the time of diagnosis, pathologic characteristics of the resected tumor, length of hospital stay, perioperative complications and mortality were reviewed. The overall survival was calculated from the time of lung cancer diagnosis. The disease free-survival was an interval between completion of CRT and detection of the tumor relapse. The progression-free survival was defined as the interval between the salvage resection and locoregional or distant recurrence of the tumor. The longterm survival was a 3-year survival after lung resection.

The statistical data analysis was performed using SPSS (version 21.0 for Windows; IBM SPSS, Inc., Chicago, IL). Descriptive statistics were applied for patient characteristics, surgical and oncologic outcome. Survival rates were calculated using the Kaplan-Meier method and compared with a long-rank test. Differences were considered to be statistically significant for $\mathrm{p}$ values of $<0.05$.

\section{Results}

The median age at the time of salvage resection was 56.2 years; 8 patients ( $89 \%$ ) were younger than 65 . Six patients $(67 \%)$ were male. Detailed pre-CRT patient characteristics are shown in the Table 1 . The median radiation dose applied to the primary tumor was $66.2 \mathrm{~Gy}$ (range 59.4 - 72 Gy). All patients received concurrent platinum-based chemotherapy in combination with vinorelbine (in 5 patients) or etoposide (in 4 patients).

Detailed post-treatment characteristics: interval between CRT and salvage resection, type of resection, tumor stage and size, percentage of viable cancer cells and postoperative complications are shown in the Table 2 . The median interval between completion of the CRT and salvage surgery was 30.2 weeks (range 12.4 - 165.7 weeks). Eight lobar or greater resections (5 lobectomies, 1 lobectomy combined with segmentectomy, 1 bilobectomy, 1 pneumonectomy) and 1 bi-segmentectomy (in patient with reduced lung function) were performed. All lung resections were completed by a systematic hilar and mediastinal lymph node dissection. Seven patients $(78 \%)$ required extended resections (1 chest wall resection, 2 vertebral column resection and reconstruction, 1 replacement of descending aorta). The complete tumor resection (R0) was achieved in all 9 cases and the pathologic examination demonstrated viable tumor cells in 8 specimens (88 \%). In one patient 27 months after definitive CRT a SUV of 3.3 was detected. But only inactive tumor tissue with extensive necrosis surrounded by fibrosis was found in the histo-pathologic examination [Fig. 1].

The median duration of the surgery was $3 \mathrm{~h} 54 \mathrm{~min}$ (range $2 \mathrm{~h} 02 \mathrm{~min}-8 \mathrm{~h} 26 \mathrm{~min}$ ). The median blood loss was $400 \mathrm{ml}$ [Range, $250-550 \mathrm{ml}$ ]. One patient developed an adult respiratory distress syndrome (ARDS) postoperatively and required prolonged mechanical ventilation. $\mathrm{He}$ was also re-operated for a post-operative empyema. One patient died on the 12th day following lobectomy with partial aortic arch resection, due to multiple organ failure.

The median postoperative length of hospital stay was 20 days (range $9-68$ days). The median postoperative follow up was 30 months (range 5.7 - 41.2 months). In two patients a locoregional recurrence 10.3 and 41 months postoperatively was evident. In other four cases distant metastases occurred. Femoral bone and adrenal gland metastases were diagnosed in one patient each 6.2 and 18.3 months, respectively. Two patients developed multiple

Table 1 Pre-treatment characteristics

\begin{tabular}{|c|c|c|c|c|c|c|c|c|}
\hline Patients & Age $(Y) / G e n d e r$ & ECOG & Tumor Size (mm) & cTNM-Stage & Histology & Radiotherapy & Chemotherapy & Reason for def. CRT \\
\hline 1 & $52 / F$ & 0 & 90 & CT4N1M0 & Adeno & 59.4 & Cisplatin/Vorelbine & \\
\hline 2 & $64 / M$ & 1 & 75 & cT3N1M0 & Squamous & 66.6 & Cisplatin/Vinorelbine & limited lung function \\
\hline 3 & $63 / M$ & 1 & 49 & CT4N1M0 & Adeno-squam & 72 & Carboplatin/Vinorelbine & Liver transplantation \\
\hline 4 & $62 / M$ & 2 & 48 & CT3N1M0 & Adeno-squam & 66 & Cisplatin/Etoposide & Liver transplantation \\
\hline 5 & $55 / F$ & 0 & 56 & CT4N1M0 & Adeno & 59.4 & Cisplatin/Etoposide & \\
\hline 6 & $37 / M$ & 0 & 37 & cT4N0M1 & Adeno-squam & 66 & Carboplatin/Vinorelbine & $\begin{array}{l}\text { Oligometastasis in } \\
\text { iliacal bone }\end{array}$ \\
\hline 7 & $71 / \mathrm{M}$ & 1 & 56 & $\mathrm{CT} 2 \mathrm{~N} 2 \mathrm{MO}$ & Adeno & 72 & Cisplatin/Etoposide & limited lung function \\
\hline 8 & $55 / F$ & 0 & 82 & CT4NOMO & Adeno & 66.2 & Cisplatin/Vinorelbine & \\
\hline 9 & $53 / \mathrm{M}$ & 0 & 87 & cT4NOMO & Adeno & 70.2 & Cisplatin/Vinorelbine & \\
\hline
\end{tabular}


Table 2 Post-treatment characteristics

\begin{tabular}{|c|c|c|c|c|c|c|}
\hline Patients & $\begin{array}{l}\text { Interval between def. RCT } \\
\text { and surgery (month) }\end{array}$ & Surgical procedure & ypTNM-stage & Tumor size (mm) & $\begin{array}{l}\text { Viable tumor } \\
\text { cells (\%) }\end{array}$ & $\begin{array}{l}\text { Perioperative } \\
\text { complication }\end{array}$ \\
\hline 1 & 27.4 & $\begin{array}{l}\text { upper bilobectomy with chest wall } \\
\text { and Th1-2 resection }\end{array}$ & TONOMO & 30 & 0 & \\
\hline 2 & 3 & extended lobectomy with chest wall & T3NOMO & 55 & 60 & $\begin{array}{l}\text { post-resectional } \\
\text { empyema, ARDS }\end{array}$ \\
\hline 3 & 10.8 & pneumectomy with aortic arch & T4NOMO & 70 & 70 & multi-organ failure \\
\hline 4 & 38.7 & S1/2- bisegmentectomy & T2aNOMO & 50 & 60 & \\
\hline 5 & 7.8 & lobectomy with chest wall & T3NOMO & 50 & 10 & \\
\hline 6 & 6.7 & $\begin{array}{l}\text { lobectomy with chest wall and } \mathrm{T} 1-3 \\
\text { resection }\end{array}$ & T4N0M1 & 10 & 50 & \\
\hline 7 & 6.7 & lobectomy & TON2MO & 50 & 10 & \\
\hline 8 & 3.5 & upper bilobectomy with chest wall & T2bNOMO & 54 & 5 & \\
\hline 9 & 5.7 & lobectomy with chest wall & T2bNOMO & 62 & 30 & \\
\hline
\end{tabular}

brain metastases 2.5 and 21.9 months postoperatively. During the follow-up interval 3 patients died due to tumor progression 12, 14 and 22.9 months after the salvage resection, whereas the patient with adrenal gland metastasis remained alive and required stereotactic body radiotherapy.

The median overall survival was 63.9 months (range 21.5 - 63.9); the median post-chemoradiation survival was 61.6 months (range 15.3 - 61.6 months). Detailed outcome is demonstrated in the Table 3 . The median postoperative long-term survival was 23 months (range 10.8 - 38 months) and the 3 years-survival rate was $47 \%$ [Fig. 2]. The median progression-free survival was 21 months (range 2.5 38 months) and 3-year progressive-free survival rate was $40 \%$.

\section{Discussion}

The rates of local NSCLC recurrence after definitive CRT are even as high as $85 \%$ at 1 year $[17,18]$. Pain, dyspnoea, haemoptysis and cough are frequent

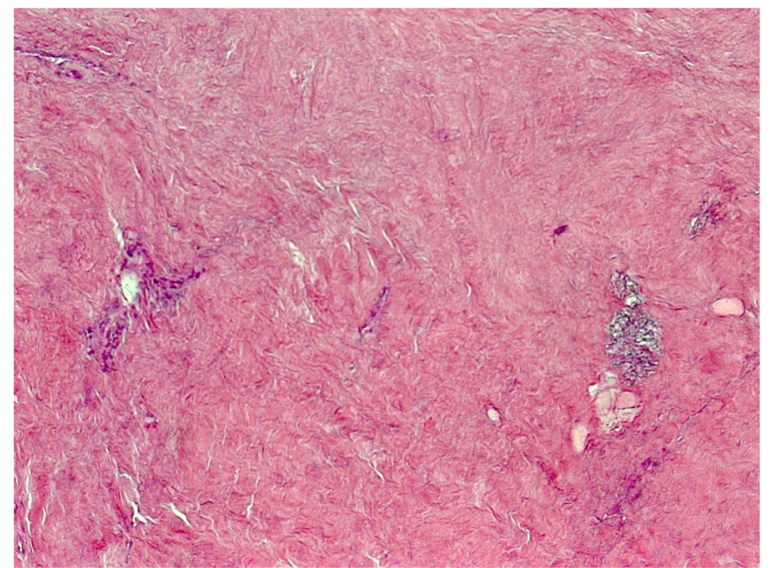

Fig. 1 Histopathologic finding with excessive fibrosis without the evidence of active tumour cells cuased by definitive chemoradiation manifestations [20]. The local NSCLC relapse remains the leading death cause after the initial therapy [3].

The difficulties in distinguishing between tumor recurrence and fibrosis or inflammatory changes on the computed tomography (CT) and FDG-PET are reported $[24,25,26]$. Dense consolidations are typical for radiation pneumonitis or fibrosis. However, the tumor re-growth must also be suspected and considered differential diagnosis [2]. The increased SUVmax values should require further clearing by $\mathrm{CT}$-guided or trans-bronchial biopsy. On the other side, the excessive fibrosis or tumor necrosis has to be expected. The fine-needle aspiration biopsy provides limited pathologic information. Therefore, distinguishing between radiation- and tumor-induced fibrosis may lead to false-negative findings. In some patients without tumor recurrence, a moderate FDG hypermetabolic activity may persist up to 2 years after CRT [22]. Therefore, the optimal treatment strategy, when the histology is unclear, remains undefined and suspected recurrence requires at least a comprehensive evaluation [21]. The right time window for the tumor biopsy and for beginning the therapy is crucial. If only focal tumor nest surrounded by necrotic mass is evident, the further course of the "remaining tumor" is unpredictable. Presence of the tumor cell nest must not indicate the recurrence as those cells may become necrotic $[19,20]$. On the other side, awaiting the radiological obvious relapse significantly decreases the overall and the progressive-free survival time $[14,15]$. Particularly, in patients with extended relapse invading the neighbouring structures, the delay in decision making decreases the chance of the tumor resectability. The biological nature of the local NSCLC relapse is less malignant in comparison to the distant recurrence. Therefore the effective local treatment is likely to be associated with prolonged overall survival and 
Table 3 Postoperative outcome

\begin{tabular}{|c|c|c|c|c|c|}
\hline Patients & $\begin{array}{l}\text { Follow-up after surgery } \\
\text { (months) }\end{array}$ & $\begin{array}{l}\text { Disease free } \\
\text { after surgery }\end{array}$ & Local recurrence & Distant recurrence & Outcome status \\
\hline 1 & 36.5 & 36.5 & & & alive tumor free \\
\hline 2 & 10.2 & 6.2 & & femur bone & died tumor related \\
\hline 3 & & & & & died, postoperatively \\
\hline 4 & 22.9 & 21.9 & & diffuse distant metastasis & died tumor related \\
\hline 5 & 18.3 & 18.3 & & adrenal gland metastasis & alive \\
\hline 6 & 13 & 10.3 & chest wall ipsilateral & & dead tumor related \\
\hline 7 & 44.2 & 41 & lymph node metastasis ipsilateral & & alive \\
\hline 8 & 18 & & & & alive tumor free \\
\hline 9 & 14 & 2.5 & & multiple brain metastasis & dead tumor related \\
\hline
\end{tabular}

long-term disease control. In addition, some authors recommend the salvage resections immediately after detecting the local recurrence [2].

The choice of a re-treatment strategy for local recurrence after the definitive CRT remains challenging. Only few therapeutic alternatives have been reported. A systematic literature review regarding the second line chemotherapy efficacy for relapsed NSCLC shows a moderate symptom control and response rates for several anticancer drugs. The median long-term survival and progressive-free survival remain under 9 and 6 months respectively [21]. In addition, Hanna et al. report only a minimal increase in survival following re-chemotherapy [22]. The reported median long-term survival after

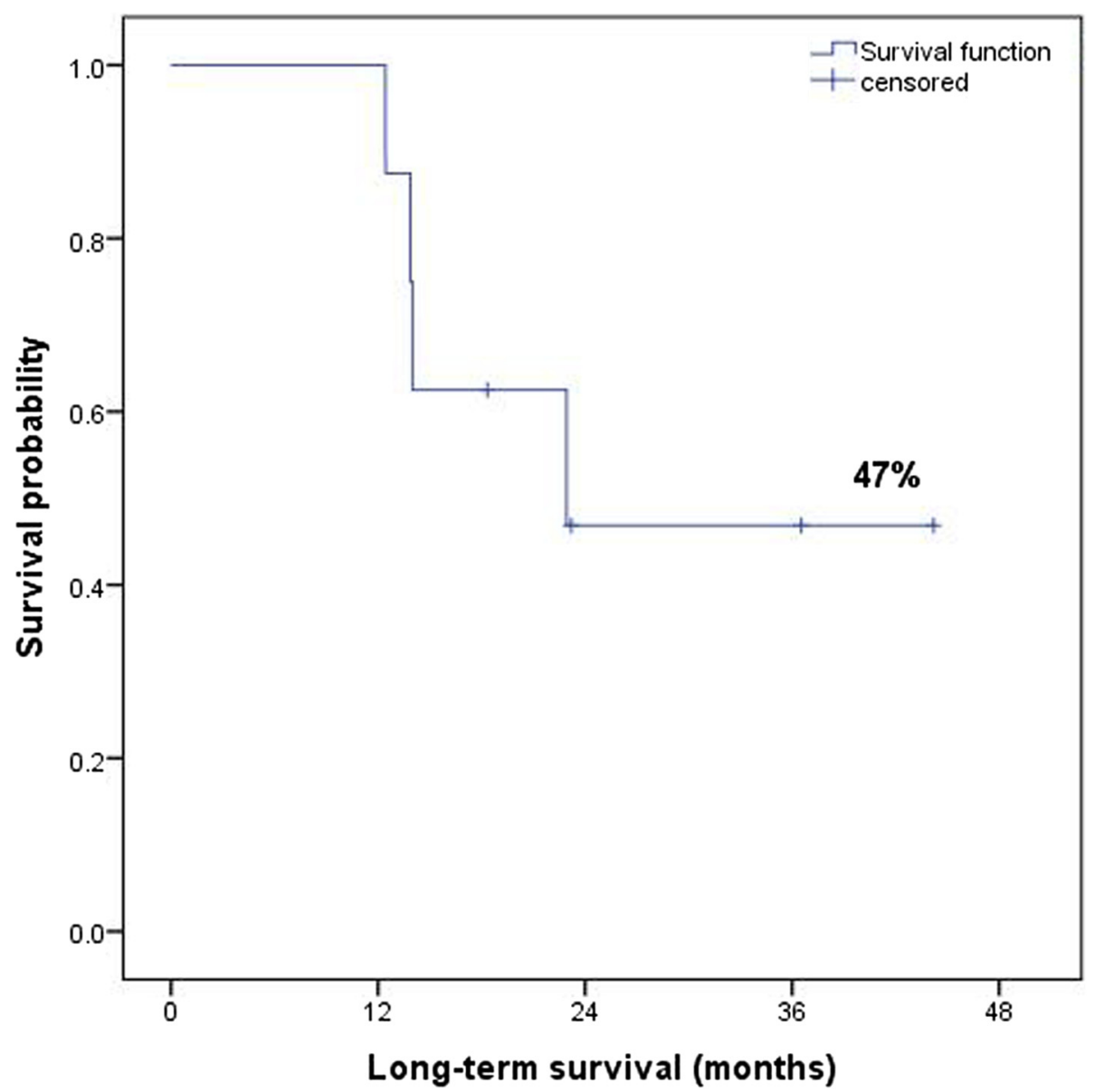

Fig. 2 Overall long-term and progressive-free survival after salvage surgery following definitive chemoradiation 
reirradiation ranges from 5 to 14 months, whereas the 2year survival rates and the 2-year progression-free survival were $27 \%$ and $21 \%$ respectively [17, 20]. Radiation tolerance of the lung, esophagus and the spinal cord limit the radiation dose that could be applied to the recurrent tumor. Particularly, the myelopathy and the late lung fibrosis have to be avoided. Jeremic et al. reviewed 11 studies of conventionally fractionated external beam reirradiation for recurrent NSCLC. The analysis showed improved overall survival after higher doses compared with low-dose reirradiation. However, this was associated with an increased rate of pneumonitis and esophagitis [3]. Toxicity strongly results from applied total and cumulative median radiation dose. However, locoregional and distant tumor control remains disappointing [22]. A radiofrequency ablation and cryoablation of the local recurrence is limited by the position of the lesion and the tumor size. The percutaneous cryoablation is recommended for more central lesions, in proximity to the large vessels [5]. The radiofrequency ablation is usually performed for lesion smaller than $3 \mathrm{~cm}$. The long-term local control is dependent on the tumor size and remains, particularly in cases with lesion greater than $3 \mathrm{~cm}$, unfavourable. Due to quick tumor progression frequently repeated invasive procedures are required [6].

Recently published reports tend to recommend salvage lung resections as feasible treatment option in absence of other management strategies for recurrent NSCLC. Due to limited experience, the patient selection criteria for "post-radiotherapy" salvage lung surgery are not clearly defined. Low postoperative mortality and complication rates despite high-dose stereotactic body radiation support the idea of salvage surgery for local recurrence in early stage NSCLC $[10,11]$. Four other reports suggest that salvage surgery is associated with prolonged survival in patients with locally recurrent or persistent tumor after definitive CRT in locally advanced NSCLC [13-16]. Bauman et al. state that the risk of salvage resection is proportional to the intensity of fibrotic response after the high-dose radiation and to the interval between radiation and resection. However, even in high-risk patients the salvage surgery was technically feasible, with reasonable results, also when performed after long-time interval [14]. In addition, some authors identified salvage lung surgery as the best option for patients with local tumor relapse, resulting in a prolonged survival $[13,23]$.

Kuzmik et al. reviewed 14 patients who completed definitive chemoradiation with median dose of $57 \mathrm{~Gy}$. After median interval between chemoradiation and surgery of 33 months [range 0-169 months] local recurrence was identified in $54 \%$ of the cases, locoregional in $15 \%$ and distant in $31 \%$. Viable tumor was found in all cases $(100 \%)$. The median postoperative survival was 9 month with the 2-year survival rate of $49 \%$ [13].

Bauman et al. described 24 patients treated initially with definitive chemoradiation with a median radiation dose of 63.9 Gy. The median time between radiation and surgery was 21 weeks. Nineteen patients $(78 \%)$ had pathological proof of viable tumor cells in the resection specimen. The median survival time for entire cohort was 30 months with estimated 3-year survival of $47 \%$ [14].

Yang et al. described a cohort of 31 patients with various indications for salvage resections. The chemoradiation was performed in $90 \%$ of the cases, with median radiation dose of $60 \mathrm{~Gy}$. The median interval between radiation and surgery was 17.7 weeks. Viable tumor cells were identified in 19 (61 \%) specimens. The median survival time for entire group was 32.5 months with 3- and 5 -year survival rates of $42 \%$ and $31 \%$, respectively. The patients with residual disease expected a median survival time of 20 months. Median survival time in patients with complete pathologic response was 60 months and differed statistically significant $(p=0.03)$ [15].

Casirhagi et al. described an extended salvage resection in a group of 24 patients. The median time between the definitive chemoradiation (mean 51 Gy) was 12 weeks and was therefore close to the time interval for surgical resection after the induction therapy. Viable tumor was found in $90 \%$ of the cases. The postoperative 3-years survival was $42 \%$ [16].

Detailed study characteristics are summarized in the Table 4.

Our group included only those patients with uncontrolled local disease (local relapse or residual tumor

Table 4 Overview to available results for salvage lung surgery after definitive chemoradiation in locally advanced NSCLC

\begin{tabular}{|c|c|c|c|c|c|c|c|c|c|c|c|c|}
\hline Autor & Year & Number & $\begin{array}{l}\text { Median } \\
\text { Age }(Y)\end{array}$ & $\begin{array}{l}\text { Median } \\
\text { Radiation } \\
\text { dose (Gy) }\end{array}$ & $\begin{array}{l}\text { Median } \\
\text { follow up } \\
\text { (month) }\end{array}$ & $\begin{array}{l}\text { Interval between } \\
\text { RCT und salvage } \\
\text { surgery (month) }\end{array}$ & $\begin{array}{l}\text { Interval between } \\
\text { RCT und salvage } \\
\text { surgery (weeks) }\end{array}$ & $\begin{array}{l}\text { Extended } \\
\text { resections } \\
(\%)\end{array}$ & $\begin{array}{l}\text { Median } \\
\text { OS (month) }\end{array}$ & $\begin{array}{l}\text { 3Y- } \\
\text { Survival } \\
(\%)\end{array}$ & $\begin{array}{l}5 Y- \\
\text { Survival } \\
(\%)\end{array}$ & $\begin{array}{l}\text { Median } \\
\text { PFS } \\
\text { (month) }\end{array}$ \\
\hline Bauman & 2008 & 24 & 60 & 63.9 & 29 & 4.6 & 20.6 & 21 & 30 & 47 & & 12 \\
\hline Kuzmik & 2013 & 14 & & & & 33 & & 21 & 9 & $49(2 Y)$ & & \\
\hline Casiraghi & 2014 & 43 & 64 & 57 & 21 & 2.7 & 12.2 & 56 & & 42 & & \\
\hline Yang & 2015 & 31 & 58 & 60 & 40 & 4 & 18 & 16 & 32.5 & 42 & 31 & 10 \\
\hline $\begin{array}{l}\text { Our } \\
\text { study }\end{array}$ & 2015 & 9 & 56 & 66 & 30 & 6.7 & 30.2 & 78 & 23 & 47 & & 21 \\
\hline
\end{tabular}


following definitive CRT). The median disease-free survival in our series was similar to the Bauman's group (6.7 vs. 5 months). In contrast, Kuzmik et al. performed salvage resections in patients with tumor recurrence in the contralateral lung (31\%) and in the other ipsilateral lobe (15\%). Only $54 \%$ out of 14 salvage lung resections were performed for local recurrence. The median disease-free survival for all patients was 33 months [13]. The ratio of extended salvage resections involving the neighbouring organs was in our group higher ( $21 \%$ by Bauman vs. $21 \%$ by Kuzmik vs. $56 \%$ Yang and $78 \%$ our group). Remarkable, despite the described differences the median long-term survival and estimated 3-year survival rates in our group were comparable with other series.

Majority of our patients developed locoregional (25\%) or distant recurrence (50\%) during the follow-up interval. Therefore the long-term disease control remains crucial and interdisciplinary decision making regarding further treatment is essential. Some important points of agreement are as follow: 1) the salvage lung surgery should be performed in patients with no other treatment alternatives; 2) the experience in this new field in the thoracic surgery remains limited; 3) a careful patient selection, particularly for extended resections, is fundamental.

Our study has a number of limitations. Small number of salvage resections was performed and the data was collected retrospectively. A control group of patients with local NSCLC recurrence after definitive CRT managed without salvage surgery was not available for the comparison.

Salvage extended thoracic surgery may represent a good therapeutic alternative in well selected cases with adequate pulmonary reserve and good performance status. The individual patient targeted approach is essential and all alternative treatment options should be discussed interdisciplinary.

\section{Conclusions}

To date, the role of the postradiochemotherapy surgical lung salvage in patients with local relapse after definitive chemoradiation for locally advanced NSCLC is poorly defined. However, salvage resections are technically feasible and are associated with reasonable survival in selected cases. The appropriate long-term tumor control determines the patient outcome. Therefore, an interdisciplinary consensus and adequate patient selection criteria for salvage surgery are required.

\section{Competing interests}

The authors declare that they have no competing interests.

\section{Authors' contributions}

WS participated in the design of the study and sequence alignment, performed the statistical analysis and drafted the manuscript. WD participated in the sequence alignment and helped to draft the manuscript.
SL conceived of the study, and participated in the design and coordination of the study. All authors read and approved the final manuscript.

\section{Author details}

'Department of Thoracic Surgery, University Hospital, Friedrich-Alexander University Erlangen-Nuremberg, Erlangen, Germany. ${ }^{2}$ Department of Radiation Oncology, University Hospital, Friedrich-Alexander University Erlangen-Nuremberg, Erlangen, Germany.

Received: 15 July 2015 Accepted: 10 January 2016

Published online: 19 January 2016

\section{References}

1. Auperin A, Le PC, Rolland E, Curran WJ, Furuse K, Fournel P, et al. Metaanalysis of concomitant versus sequential radiochemotherapy in locally advanced non-small cell lung cancer. J Clin Oncol. 2010;28(1):2181-90.

2. Fietkau R, Semrau S. Stage III: definitive chemoradiotherapy. Front Radiat Ther Oncol. 2010;42:122-34.

3. Jeremic B, Videtic G. Chest reirradiation with external beam radiotherapy for locally recurrent non-small cell lung cancer: A review. Int J Radiation Oncology Biol Phys. 2011;80(4):969-77.

4. Brandley J. New territory. Surgical salvage for stereotactic body radiation therapy failures in lung cancer. J Thorac Oncol. 2010;5(12):1879-80.

5. Goto T, Izumi Y, Nakatsuka S, Nomori H. Percutaneous cryoablation as a salvage therapy for local recurrence of lung cancer. Ann Thorac Surg. 2012;94:e31-3.

6. Schoellnast H, Deodhar A, Hsu M, Moskowitz C, Nehmeh S, Thronton R, et al. Recurrent non-small cell lung cancer: evaluation of CT-guided radiofrequency ablation as salvage surgery. Acta Radiol. 2012;53(8):893-9.

7. Habr-Gama A, Gama-Rodrigues J, Sao Juliao GP, Proscurshim I, Sabbagh C, Lynn PB, et al. Local recurrence after complete response and watch and wait in rectal cancer after neoadjuvant chemoradiation: impact of salvage therapy on local disease control. Int J Radiation Oncol Biol Phys. 2014;88(4):822-8.

8. Raptis D, Schneider I, Matzel KE, Ott O, Fietkau R, Hohenberger W. The differential diagnosis and interdinsciplinary treatment of anal carcinoma. Dtsch Artebl Int. 2015;112:243-9.

9. Glynne-Jones R, Hughes R. Critical appraisal of the "wait and see" approach in rectal cancer for clinical complete responders after chemoradiation. $\mathrm{Br}$ J Surg. 2012;99:897-909.

10. Neri S, Takahashi Y, Terashi T, Hamakawa H, Tomii K, Katakami N, et al. Surgical treatment of local recurrennce after stereotactic body radiotherapy for primary and metastatic lung cancers. J Thorac Oncol. 2010;5(12):2003-7.

11. Chen F, Matsuo Y, Yoshizawa A, et al. Salvage lung resection for non-small cell lung cancer after stereotactic body radiotherapy in initially operable patients. J Thorac Oncol. 2010;5(12):1999-2002.

12. Van Schil P. Salvage surgery after stereotactic radiotherapy. A new challenge for thoracic surgeons. J Thorac Oncol. 2010;5(12):1881-2.

13. Kuzmik GA, Detterbeck FC, Decker RH, Boffa DJ, Wang Z, Oliva IB, et al. Pulmonary resections following prior definitive chemoradiation therapy are associated with acceptable survival. Eur J Cardiothorac Surg. 2013;44(1):e66-70.

14. Bauman JE, Mulligan MS, Martins RG, Kurland BF, Eaton KD, Wood DE. Salvage lung resection after definitive radiation (>59 Gy) for non-small cell lung cancer: surgical and oncologic outcomes. Ann Thorac Surg. 2008;86(5):1632-8.

15. Yang CFJ, Meyerhoff RR, Stephens SJ, Singhapricha T, Toomey CB, Anderson $\mathrm{KL}$, et.al. Long-term outcome for lobectomy for non-small cell lung cancer after definitive radiation treatment. Ann Thorac Surg 2015, in Press

16. Gasiraghi M, Solli R, De Marinis F, Petrella F, Guarize J, Spaggiari L, et al. Salvage surgery after definitive chemoradiotherapy for non-small cell cancer [abstract]. Interact CardioVasc Thorac Surg. 2014;19(Suppl I):S48-9.

17. Wu K, Jiang G, Qian H, Wang LJ, Yang HJ, Fu XL, et al. Three-dimensional conformal radiotherapy for locoregionally recurrent lung carcinoma after stereotactic beam irradiation: a prospective phase I-II clinical trial. Int J Radiation Oncology Biol Phys. 2003;57(5):1345-50.

18. Gressen E, Werner-Wasik M, Cohn J, Topham A, Curran WJ Jr. Thoracic reirradiation for symptomatic relief after prior radiotherapeutic management for lung cancer. Am J Clin Oncol. 2000;23(2):160-3.

19. Okamoto Y, Murakami MM, Yoden E, Sasaki R, Okuno Y, Nakajima T, et al. Reirrradiation for locally recurrent lung cancer previously treated with radiation therapy. Int J Radiation Oncology Biol Phys. 2002;52(2):390-6.

20. Noble J, Ellis PM, Mackay JA, Evans WK. Second-line or subsequent systemic therapy for recurrent or progressive non-small lung cancer: a systematic review and practice quideline. J Thorac Oncol. 2006; 1 (9):1042-58. 
21. Hanna N. Second-line treatment of non-small cell lung cancer: big targets, small progress; small targets, big process? J Thorac Oncol. 2006;1 (9):927-8.

22. McAvoy S, Cuira K, Wei C, Rineer J, Liao Z, Chang JY, et al. Definitive reirradiation for locoregionally recurrent non-small cell lung cancer with proton beam therapy or intensity modulated radiation therapy: predictors of high-grade toxicity and survival outcomes. Int I Radiat Oncol Biol Phys 2014, in Press

23. Uramoto H, Tanaka F. Salvage thoracic surgery in patients with primary lung cancer. Lung cancer. 2014;84:151-5.

24. Taira N, Kawabata T, Ichi T, Kushi K, Yohena T, Kawasaki H, et al. Salvage operation for late recurrence after stereotactic body radiotherapy for lung cancer: two patients with no viable cancer cells. Ann Thorac Sirg. 2014;97: 2167-71.

25. Trovo M, Linda A, El Naga I, Javidan-Nejad C, Bradley J et al. Early and late lung radiographic injury following stereotactic body radiation therapy. Lung Cancer. 2010;69:77-85.

26. Allibhai Z, Cho BCJ, Taremi M, Atallah S, Hope A, Hwang D, et al. Surgical salvage following stereotactic body radiotherapy for early-stage NSCLC. Eur Respir J. 2012;39(4):1039-42.

\section{Submit your next manuscript to BioMed Central} and we will help you at every step:

- We accept pre-submission inquiries

- Our selector tool helps you to find the most relevant journal

- We provide round the clock customer support

- Convenient online submission

- Thorough peer review

- Inclusion in PubMed and all major indexing services

- Maximum visibility for your research

Submit your manuscript at www.biomedcentral.com/submit 